\title{
Prevalence of overweight/obesity, anaemia and their associations among female university students in Dubai, United Arab Emirates: a cross-sectional study
}

\author{
Haleama Al Sabbah (10 \\ Public Health Nutrition Department, Zayed University, Dubai, United Arab Emirates
}

(Received 29 May 2020 - Accepted 4 June 2020)

Journal of Nutritional Science (2020), vol. 9, e26, page 1 of 6

doi:10.1017/jns.2020.23

Abstract

The present study assessed the associations of overweight, obesity and anaemia with selected lifestyle factors, total body fat and abdominal obesity among female university students in Dubai. A total of 251 female students from a national university in Dubai participated in the present study. Weight, height, waist circumference, $\mathrm{Hb}$ level and total body fat percentage were measured. Participants also completed a self-reported questionnaire that included items related to the factors of obesity, anaemia and lifestyle. The study was approved by the University Ethical Committee. Almost one-third of the participants were overweight/obese; $8.5 \%$ had abdominal obesity while $18.1 \%$ had anaemia. Out of the total, $71.7 \%$ reported that they have irregular meals and the highest percentages were found among obese $(89.3 \%)$ and overweight $(78.0 \%)$ compared with normal-weight $(65 \cdot 4 \%)$ students $(P<0 \cdot 05)$. Overweight/ obese students reported that they exercise more than those of normal weight $(P=0 \cdot 05)$. Students with anaemia reported less exercise than students without anaemia $(P=0 \cdot 05)$. Also, the percentage of total body fat was found to be the highest $(38.9 \%)$ among students with anaemia $(P<0 \cdot 05)$. Overweight, obesity and anaemia are prevalent among female university students. Anaemia seems to be associated with the percentage of total body fat, lack of physical activity and junk food. Further studies are required to investigate the detailed dietary habits of overweight and obese young adult females with anaemia.

Key words: Anaemia: Females: Obesity: Overweight: United Arab Emirates

Obesity and overweight are major public health problems that are associated with a higher mortality rate worldwide ${ }^{(1)}$. Obesity is a medical condition in which excess body fat has accumulated to the extent that it may have an adverse effect on health, leading to reduced life expectancy and/or increased health problems ${ }^{(2)}$. Previous studies have shown that it is more prevalent among women than men and that young adult females in general are at an increased risk of developing anaemia $^{(2-4)}$.

A decreased count of erythrocytes and diminished $\mathrm{Hb}$ levels are often what characterise anaemia ${ }^{(3)}$. The occurrence of anaemia is enhanced by factors including puberty, excessive menstrual losses, giving birth, poor dietary choices and insufficient $\mathrm{Fe}$ intake from animal-based foods ${ }^{(4)}$. Anaemia has been linked to several health consequences such as impaired physical and cognitive performance, and increased risk of maternal and child mortality ${ }^{(3,5)}$. Food habits can result in anaemia and increase the risk of obesity, particularly among young females ${ }^{(6-}$ 10). Factors involved include skipping breakfast, reduced intake of fruits and vegetables and increased consumption of sugary drinks and high-energy foods ${ }^{(11,12)}$. Several previous studies indicated that anaemia is more prevalent among overweight and obese adults in general ${ }^{(8,9,13,14)}$, and also among overweight children, adolescents and young adults ${ }^{(8,15,16)}$.

A study in the Kingdom of Saudi Arabia showed that the prevalence of anaemia among female university students was

Abbreviations: UAE, United Arab Emirates; WC, waist circumference.

Corresponding author: Haleama Al Sabbah, email haleemah.alsabah@zu.ac.ae

(C) The Author(s), 2020. Published by Cambridge University Press on behalf of The Nutrition Society. This is an Open Access article, distributed under the terms of the Creative Commons Attribution licence (http://creativecommons.org/licenses/by/4.0/), which permits unrestricted re-use, distribution, and reproduction in any medium, provided the original work is properly cited. 
$23.9 \%{ }^{(17)}$. Given the health consequences of anaemia, its increased prevalence among females and the obesity epidemic worldwide, studying the prevalence of obesity and overweight and their associations with $\mathrm{Hb}$ level and food habits is a major part of the present study to guide future studies and interventions.

International and regional studies show an increase in obesity rates and highlight that factors associated with it are multifactorial particularly among university students, but there has been little relevant research relating anaemia to obesity and total body fat in the United Arab Emirates (UAE) ${ }^{(1,2,15-17)}$.

There are no data available at all in the literature from the UAE. Lack of studies from the UAE population makes the present study very important to be as a reference and base for researchers and decision makers. The present study will add new knowledge to the international studies about Emirati people living in the UAE. Moreover, the present study will add estimates from the Global Burden of Disease Study and other researchers and decision makers might use this data to design later national data and other studies. The main objective of the present study is to assess the prevalence of overweight, obesity, anaemia and their associations with the eating habits, physical activity and total body fat among female students at one of the national universities in the UAE.

\section{Methods}

\section{Study design}

A cross-sectional study was conducted on 251 female students at one of the national universities in the UAE from 24 November to 10 December 2014. The present study was conducted according to the guidelines laid down in the Declaration of Helsinki and all procedures involving human subjects were approved by Zayed University Ethical Committee (no. ZU14_052_F). Written informed consent was obtained from all subjects. Students were informed that participation in the study is voluntary, and before data collection students were provided with full information about the study and given the opportunity for potential participants to ask any question before they signed the written informed consent.

\section{Population and sampling}

The total number of female students enrolled at the university in autumn 2014 at the Dubai campus was approximately 3000 Emirati undergraduate students. In order to have a $10 \%$ of the total population representative sample from all colleges, the estimated sample size was 300 students selected by using a systematic random sampling from: Colleges of Arts, Business, Communication and Media, Education, Sustainability and Human Sciences, Technology, and University College. Students' names and numbers were imported from the university's Banner Web in the 2014 autumn semester. An interval of 10 was used to select students randomly from the imported list and a random starting number was obtained by using Excel. In addition, the Students' Affairs Office at the university and all university teachers were informed about the present study in order to encourage students to participate. Since they were blinded from knowing who was selected, they advertised the study to all their students.

The sample size calculation was based on the formula of infinite population sample size (SS) equation: $\mathrm{SS}=\left(\tau^{2} \times p \times\right.$ q) $/ d^{2}$; where $z$ is the $\alpha$ risk expressed in the $z$-score, $p$ is the predicted prevalence, $q$ is $(1-p)$ and $d$ is the absolute precision. In the present study, a CI of $95 \%(\alpha=0 \cdot 05)$, hence a $z$-score of 1.96 , a predicted prevalence of anaemia of $p=0.20$ and an absolute precision of $d=0.05$ were used. Thus, a sample of 246 students was required.

\section{Data collection}

A total of 307 randomly selected students were invited via emails to come to the University Nutrition Laboratory and participate in completing the study questionnaire and to measure their weight, height, waist circumference (WC), total body fat and $\mathrm{Hb}$ level. One female nurse and two research assistants were recruited and trained to take the measurements for the participating students. In total, 251 students came to the laboratory and agreed to participate in the present study, resulting in a response rate of $81.8 \%$. Two senior students on their final year from the Department of Public Health Nutrition who received training on nutrition education under the supervision of a professor in nutrition were giving nutrition education to students who had low $\mathrm{Hb}$ level and students with obesity or underweight. In addition, students with a low $\mathrm{Hb}$ level were referred to the university health centre for follow-up.

\section{Procedures and measurements}

Participants completed a self-reporting questionnaire that included items related to obesity, anaemia and lifestyle. The questionnaire was developed based upon information existing in the related literature and validated by a professor in nutrition then piloted on twenty students who are not included in the present study analysis.

Weight and height were measured by using calibrated scales and stadiometers, WC was measured under clothing by flexible measuring tapes. Height and WC were measured to the nearest $0.5 \mathrm{~cm}$. Body weight was measured to the nearest $0.1 \mathrm{~kg}$. The participants were weighed with a minimum of clothing and no shoes. BMI was calculated by dividing weight in $\mathrm{kg}$ by the height in metres squared $\left(\mathrm{kg} / \mathrm{m}^{2}\right)$. BMI was categorised into underweight $\left(\mathrm{BMI}<18.5 \mathrm{~kg} / \mathrm{m}^{2}\right)$, normal weight (BMI = $\left.18.5-24.9 \mathrm{~kg} / \mathrm{m}^{2}\right)$, overweight $\left(\mathrm{BMI}=25-29.9 \mathrm{~kg} / \mathrm{m}^{2}\right)$ and obese (BMI $\left.\geq 30 \mathrm{~kg} / \mathrm{m}^{2}\right)^{(2)}$. Abdominal obesity was assessed using the WC measurement and was based upon the WHO criteria for cut-offs (WC $\geq 88 \mathrm{~cm}$ for females and $\geq 102 \mathrm{~cm}$ for males ${ }^{(2)}$. Total body fat percentage was measured by a Tanita machine at the university nutrition laboratory.

$\mathrm{Hb}$ level was measured by using a Hemocue analyser. Blood samples were collected by a professional nurse from participating students using finger pricks. According to the WHO, the level of anaemia among non-pregnant women aged 15 years old and above was defined by $\mathrm{Hb}$ level below $120 \mathrm{mg} / \mathrm{l}^{(18)}$. 


\section{Statistical analyses}

Data obtained were analysed using the SPSS statistical package (IBM). The $\chi^{2}$ test was used to compare frequencies between categorical variables. The significance level was set at $0 \cdot 05$.

\section{Results}

Table 1 shows the sample's sociodemographic characteristics. The mean age was 23.1 (SD $5 \cdot 3$ ) years. The majority perceived having a moderate economic status $(82.3 \%)$. Of the total, $7 \cdot 6 \%$ reported being married and $4 \%$ were engaged.

The prevalence of overweight and obesity was found to be $29.3 \%$ (17.4 and $11.9 \%$, respectively). The prevalence of abdominal obesity (WC $\geq 88 \mathrm{~cm}$ ) was $8.5 \%$, with a mean WC of $71.6(S D 10.5) \mathrm{cm}$. The prevalence of anaemia was $18 \cdot 1 \%$, with a mean $\mathrm{Hb}$ level of 129.5 (SD 13) $\mathrm{mg} / \mathrm{l}$, ranging between 86 and $161 \mathrm{mg} / 1$ (Table 2).

Table 3 shows the sociodemographic characteristics of the study participants by weight status and $\mathrm{Hb}$ level. Females aged 20 years or younger were more likely to be underweight $(20.9 \%)$, while females older than 20 years were more likely to be overweight $(20 \cdot 8 \%)$. In addition, anaemia was more prevalent among female students aged $>20$ years old $(23 v .14 .5 \%)$, with no significant difference $(P=0 \cdot 066)$.

The prevalence of underweight was found to be the highest among female students in their 1 st year of study (30\%). No association was found between overweight, obesity and year of study (Table 3). Overweight, obesity and anaemia were more prevalent among female students who perceived that their families have moderate economic status $(17 \cdot 4,13 \cdot 3$ and $19.7 \%$, respectively) than those who perceived that their families have high economic status $(14.4,4.3$ and $11.9 \%$, respectively) (Table 3).

Table 4 shows that abdominal obesity (WC $\geq 88 \mathrm{~cm}$ ) was more prevalent among obese students than among overweight and normal-weight students $(P<0 \cdot 001)$. The percentage of total body fat measured by the Tanita machine was the highest among obese and overweight students, while only $2.9 \%$ among normal-weight students $(P<0 \cdot 001)$. Moreover, the

Table 1. Sociodemographic characteristics ( $n$ 251) (Numbers of subjects and percentages)

\begin{tabular}{lrr}
\hline & $n$ & $\%$ \\
\hline Age & & \\
$\leq 20$ years & 143 & $57 \cdot 7$ \\
$>20$ years & 105 & $42 \cdot 3$ \\
Academic level & & \\
1st year & 40 & $15 \cdot 9$ \\
2nd year & 47 & $18 \cdot 7$ \\
3rd year & 73 & $29 \cdot 1$ \\
4th year & 91 & $36 \cdot 3$ \\
Economic status perception & & \\
High & 44 & $17 \cdot 7$ \\
Moderate & 204 & $82 \cdot 3$ \\
Marital status & & \\
Single & 221 & $48 \cdot 4$ \\
Engaged & 10 & $7 \cdot 6$ \\
Married & 19 & \\
\hline
\end{tabular}

Table 2. Prevalence of overweight, obesity and anaemia (Numbers of subjects and percentages, ranges, and mean values and standard deviations)

\begin{tabular}{|c|c|c|c|c|c|}
\hline Variables & $n$ & $\%$ & Range & Mean & SD \\
\hline Measured BMI $\left(\mathrm{kg} / \mathrm{m}^{2}\right)$ & & & $14 \cdot 2-43 \cdot 7$ & $23 \cdot 1$ & $5 \cdot 3$ \\
\hline Underweight & 37 & $17 \cdot 0$ & & & \\
\hline Normal weight & 117 & 53.7 & & & \\
\hline Overweight & 38 & $17 \cdot 4$ & & & \\
\hline Obese & 26 & 11.9 & & & \\
\hline Waist (cm) & & & $54 \cdot 0-107 \cdot 3$ & $71 \cdot 6$ & $10 \cdot 5$ \\
\hline$<88$ & 216 & 91.5 & & & \\
\hline$\geq 88$ & 20 & 8.5 & & & \\
\hline Total & 236 & 100 & & & \\
\hline $\mathrm{Hb}$ level (mg/l) & & & $86-161$ & 129.5 & 13 \\
\hline$\geq 120$ (no anaemia) & 195 & 81.9 & & & \\
\hline$<120$ (anaemic) & 43 & $18 \cdot 1$ & & & \\
\hline
\end{tabular}

percentage of total body fat was found to be the highest $(38.9 \%)$ among students with anaemia $(P<0 \cdot 05)$ (Table 4$)$.

Obese and overweight students reported that they exercise (at least $60 \mathrm{~min} / \mathrm{d}$ ) more than normal-weight and underweight students $(P=0 \cdot 05)$. In addition, students with anaemia reported less exercise $(60 \mathrm{~min} / \mathrm{d})$ than students without anaemia $(P=0 \cdot 05)$. More than two-thirds of the students $(71.7 \%)$ reported that they follow irregular meals pattern. Obese and overweight students reported having irregular meals patterns more than normal-weight students $(P<0 \cdot 05)$ (Table 4).

More than half of the obese $(53.6 \%$ ) and $43.9 \%$ of the overweight students reported that they were currently on a diet to lose weight, while only $17 \cdot 5 \%$ of the normal-weight and $2 \cdot 3 \%$ of the underweight students reported that they were dieting $(P<0 \cdot 001)$. In addition, about $60 \%$ of the participants reported that they prefer junk food and the highest percentage was found among obese students $(71.4 \%)$, followed by overweight students $(63.4 \%)$. More than two-thirds $(72.1 \%)$ of the anaemic students stated junk food preference compared with $57.4 \%$ of the non-anaemic $(P=0.053)$ (Table 4).

\section{Discussion}

The present study aimed to assess the prevalence of overweight, obesity and anaemia and their associations with sociodemographic characteristics, lifestyle, total body fat and abdominal obesity among female university students in Dubai. Based on our current knowledge, this is the first study conducted among female university students in Dubai covering this topic. A systematic random sampling approach was used to ensure that the selected students were representative of all the university's female students and findings of the present study can be generalised to all UAE and Gulf Cooperation Council university's female students.

Both obesity and anaemia are worldwide epidemics affecting vulnerable populations ${ }^{(19)}$. In the present study, $17 \cdot 4 \%$ of the participants were found to be overweight, 11.9\% were obese and $8.5 \%$ had abdominal obesity following the WHO classification ${ }^{(2)}$. Abdominal obesity prevalence has not been 
Table 3. Sociodemographic characteristics by weight status and $\mathrm{Hb}$ level (Percentages of subjects)

\begin{tabular}{|c|c|c|c|c|c|c|c|c|}
\hline \multirow[b]{2}{*}{ Characteristic } & \multicolumn{4}{|c|}{ Weight status (\%) } & \multirow[b]{2}{*}{$P^{\star}$} & \multicolumn{2}{|c|}{$\mathrm{Hb}$ level $(\%)$} & \multirow[b]{2}{*}{$P^{\star}$} \\
\hline & Underweight ( $n 37)$ & Normal weight $(n 117)$ & Overweight (n38) & Obese $(n 26)$ & & Anaemia ( $n 43)$ & Normal ( $n$ 195) & \\
\hline \multicolumn{9}{|l|}{ Age } \\
\hline$\leq 20$ years & $20 \cdot 9$ & $53 \cdot 2$ & $14 \cdot 4$ & 11.5 & \multirow[t]{2}{*}{0.463} & 14.5 & $85 \cdot 5$ & \multirow[t]{2}{*}{0.066} \\
\hline$>20$ years & 14.9 & 52.5 & $20 \cdot 8$ & 11.9 & & 23.0 & $77 \cdot 0$ & \\
\hline \multicolumn{9}{|l|}{ Academic level } \\
\hline 1st year & $30 \cdot 0$ & $40 \cdot 0$ & $17 \cdot 5$ & $12 \cdot 5$ & \multirow[t]{4}{*}{0.736} & $20 \cdot 5$ & 79.5 & \multirow[t]{4}{*}{0.233} \\
\hline 2nd year & $17 \cdot 0$ & 53.2 & 14.9 & 14.9 & & 8.5 & 91.5 & \\
\hline 3rd year & $15 \cdot 7$ & $57 \cdot 1$ & $17 \cdot 1$ & $10 \cdot 0$ & & $23 \cdot 2$ & $76 \cdot 8$ & \\
\hline 4th year & $15 \cdot 7$ & 55.4 & $18 \cdot 1$ & $10 \cdot 8$ & & $18 \cdot 1$ & 81.9 & \\
\hline \multicolumn{9}{|c|}{ Economic status perception } \\
\hline High & $16 \cdot 8$ & 64.5 & 14.4 & 4.3 & \multirow[t]{2}{*}{0.324} & 11.9 & $88 \cdot 1$ & \multirow[t]{2}{*}{0.168} \\
\hline Moderate & $17 \cdot 9$ & $51 \cdot 3$ & $17 \cdot 4$ & $13 \cdot 3$ & & 19.7 & $80 \cdot 3$ & \\
\hline \multicolumn{9}{|l|}{ Marital status } \\
\hline Single & 18.5 & $51 \cdot 7$ & $16 \cdot 6$ & $13 \cdot 3$ & \multirow[t]{3}{*}{0.432} & $16 \cdot 7$ & $83 \cdot 3$ & \multirow[t]{3}{*}{0.492} \\
\hline Engaged & $16 \cdot 7$ & $55 \cdot 6$ & $27 \cdot 8$ & 0.0 & & $27 \cdot 8$ & $72 \cdot 2$ & \\
\hline Married & $20 \cdot 0$ & $70 \cdot 0$ & $10 \cdot 0$ & 0.0 & & $20 \cdot 0$ & $80 \cdot 0$ & \\
\hline
\end{tabular}

${ }^{*} \chi^{2}$ Test.

Table 4. Associations of weight status and $\mathrm{Hb}$ level with waist circumference, percentage of total body fat and selected lifestyle characteristics (Numbers of subjects and percentages)

\begin{tabular}{|c|c|c|c|c|c|c|c|c|c|c|}
\hline \multirow[b]{2}{*}{ Characteristic } & \multicolumn{2}{|c|}{ Total } & \multicolumn{4}{|c|}{ Weight status (\%) } & \multirow[b]{2}{*}{$P^{\star}$} & \multicolumn{2}{|c|}{$\mathrm{Hb}$ level (\%) } & \multirow[b]{2}{*}{$P^{\star}$} \\
\hline & $n$ & $\%$ & Under & Norm & Over & Obese & & Anaemia & Normal & \\
\hline \multicolumn{11}{|l|}{ Waist (cm) } \\
\hline$<88$ & 216 & 91.5 & $100 \cdot 0$ & $99 \cdot 2$ & 92.7 & $40 \cdot 7$ & \multirow{3}{*}{$P<0.001$} & 90.5 & $91 \cdot 4$ & \multirow[t]{3}{*}{0.507} \\
\hline$\geq 88$ & 20 & 8.5 & 0.0 & 0.8 & $7 \cdot 3$ & $59 \cdot 3$ & & 9.5 & $8 \cdot 6$ & \\
\hline Total & 236 & 100 & 100 & 100 & 100 & 100 & & 100 & 100 & \\
\hline \multicolumn{11}{|l|}{ Total body fat } \\
\hline Athletic (8-15\%) & 12 & 5.9 & $28 \cdot 2$ & 1.0 & 0.0 & 0.0 & \multirow{6}{*}{$P<0.001$} & $8 \cdot 3$ & 5.5 & \\
\hline Good (16-23\%) & 39 & $19 \cdot 2$ & 61.5 & 14.4 & $0 \cdot 0$ & 0.0 & & $25 \cdot 0$ & $18 \cdot 3$ & \multirow[t]{5}{*}{0.030} \\
\hline Acceptable (24-30\%) & 63 & $31 \cdot 1$ & $10 \cdot 3$ & $55 \cdot 8$ & $3 \cdot 0$ & $0 \cdot 0$ & & $25 \cdot 0$ & $32 \cdot 9$ & \\
\hline Overweight (31-36\%) & 38 & $18 \cdot 7$ & 0.0 & $26 \cdot 0$ & $30 \cdot 3$ & 3.7 & & $2 \cdot 8$ & $21 \cdot 3$ & \\
\hline Obese ( $\geq 37 \%)$ & 51 & $25 \cdot 1$ & 0.0 & $2 \cdot 9$ & $66 \cdot 7$ & $96 \cdot 3$ & & 38.9 & $22 \cdot 0$ & \\
\hline Total & 203 & 100 & 100 & 100 & 100 & 100 & & 100 & 100 & \\
\hline \multicolumn{11}{|l|}{ Sleeping $(\mathrm{h} / \mathrm{d})$} \\
\hline Less than 7 & 91 & 37 & $37 \cdot 2$ & $33 \cdot 3$ & $36 \cdot 6$ & $46 \cdot 4$ & \multirow{4}{*}{0.669} & 43.9 & $35 \cdot 4$ & \multirow[t]{4}{*}{0.560} \\
\hline $7-8$ & 123 & 50 & $48 \cdot 8$ & $55 \cdot 3$ & 43.9 & $42 \cdot 9$ & & 43.9 & $52 \cdot 6$ & \\
\hline More than 8 & 32 & 13 & $14 \cdot 0$ & $11 \cdot 4$ & 19.5 & $10 \cdot 7$ & & $12 \cdot 2$ & $12 \cdot 0$ & \\
\hline Total & 246 & 100 & 100 & 100 & 100 & 100 & & 100 & 100 & \\
\hline \multicolumn{11}{|l|}{ Exercise $\geq 60 \mathrm{~min}$} \\
\hline Yes & 140 & 56 & $38 \cdot 6$ & $56 \cdot 7$ & 67.5 & $60 \cdot 7$ & \multirow[t]{3}{*}{0.050} & $44 \cdot 2$ & $59 \cdot 3$ & \multirow[t]{3}{*}{0.050} \\
\hline No & 110 & 44 & $61 \cdot 4$ & $43 \cdot 3$ & 32.5 & $39 \cdot 3$ & & $55 \cdot 8$ & $40 \cdot 7$ & \\
\hline Total & 250 & 100 & 100 & 100 & 100 & 100 & & 100 & 100 & \\
\hline \multicolumn{11}{|l|}{ Meal pattern } \\
\hline Always regular & 71 & $28 \cdot 3$ & $22 \cdot 7$ & $34 \cdot 6$ & $22 \cdot 0$ & $10 \cdot 7$ & \multirow[t]{3}{*}{0.039} & $23 \cdot 3$ & $28 \cdot 7$ & \multirow[t]{3}{*}{0.301} \\
\hline Irregular & 180 & $71 \cdot 7$ & $77 \cdot 3$ & $65 \cdot 4$ & $78 \cdot 0$ & $89 \cdot 3$ & & $76 \cdot 7$ & $71 \cdot 3$ & \\
\hline Total & 251 & 100 & 100 & 100 & 100 & 100 & & 100 & 100 & \\
\hline \multicolumn{11}{|l|}{ Breakfast pattern } \\
\hline Regular & 105 & $41 \cdot 8$ & 29.5 & $46 \cdot 5$ & $43 \cdot 9$ & $39 \cdot 3$ & \multirow[t]{4}{*}{0.439} & $41 \cdot 9$ & $43 \cdot 1$ & \multirow[t]{4}{*}{0.942} \\
\hline Irregular & 129 & $51 \cdot 4$ & 63.6 & $45 \cdot 7$ & 53.7 & $53 \cdot 6$ & & $51 \cdot 2$ & $51 \cdot 3$ & \\
\hline I don't eat breakfast & 17 & $6 \cdot 8$ & $6 \cdot 8$ & 7.9 & $2 \cdot 4$ & $7 \cdot 1$ & & $7 \cdot 0$ & $5 \cdot 6$ & \\
\hline Total & 251 & 100 & 100 & 100 & 100 & 100 & & 100 & 100 & \\
\hline Dieting to lose weight & & & & & & & & & & \\
\hline Yes & 61 & $24 \cdot 4$ & $2 \cdot 3$ & $17 \cdot 5$ & 43.9 & $53 \cdot 6$ & $P<0.001$ & $18 \cdot 6$ & $25 \cdot 3$ & 0.237 \\
\hline No & 189 & $75 \cdot 6$ & $97 \cdot 7$ & 82.5 & $56 \cdot 1$ & $46 \cdot 4$ & & $81 \cdot 4$ & $74 \cdot 7$ & \\
\hline Total & 250 & 100 & 100 & 100 & 100 & 100 & & 100 & 100 & \\
\hline Prefer junk food & & & & & & & & & & \\
\hline Yes & 150 & $59 \cdot 8$ & $59 \cdot 1$ & $58 \cdot 3$ & 63.4 & 71.4 & 0.606 & $72 \cdot 1$ & 57.4 & 0.053 \\
\hline No & 101 & $40 \cdot 2$ & 40.9 & $41 \cdot 7$ & $36 \cdot 6$ & $28 \cdot 6$ & & $27 \cdot 9$ & $42 \cdot 6$ & \\
\hline Total & 251 & 100 & 100 & 100 & 100 & 100 & & 100 & 100 & \\
\hline
\end{tabular}

Under, underweight; Norm, normal weight; Over, overweight.

${ }^{*} \chi^{2}$ Test. 
reported before among female university students in Dubai. Abdominal obesity is associated with increased risk of type 2 diabetes, CVD, sleep apnoea and premature death ${ }^{(20)}$. The prevalence of obesity found in the present study is close to the WHO's estimates and highlights the importance of obesity as a public health problem ${ }^{(21)}$.

About one-fifth $(18.1 \%)$ of the study participants were anaemic based on the WHO cut-off values ${ }^{(22)}$. Hb concentration can indicate the severity of anaemia ${ }^{(18)}$. The present study found that a high level of total body fat was associated with anaemia $(P=0 \cdot 030)$. Also, low levels of exercise and preferences to eat junk food were found to be associated with anaemia. This might be explained by the fact that poor dietary choices - which has been reported in the present study as high preference for 'junk food' - are generally deficient in essential nutrients especially $\mathrm{Fe}$ or have substances that reduce $\mathrm{Fe}$ absorption. The students with anaemia reported a high tendency to engage in dieting behaviour at the time of the study, which can explain our results if they were following fad diets that are based on eliminating major food groups. Also, students with anaemia have an increased percentage of total body fat which can make exercise harder in addition to their anaemia.

Obesity may stimulate anaemia by inhibiting dietary $\mathrm{Fe}$ uptake from the duodenum ${ }^{(23)}$. Several analyses have demonstrated an association between lower serum Fe concentrations with higher BMI, particularly in women ${ }^{(21)}$. The present study found significant associations between anaemia and total body fat. Obese and underweight students were found to be two times more likely to have anaemia compared with normalweight students. This might be due to the fact that anaemia is one of the most common nutritional deficiency disorders ${ }^{(24,25)}$.

The nature of the cross-sectional study design poses a challenge in inferring causal relationships, especially when examining temporality. Whether obesity has led to anaemia and lack of exercise or poor diet choices and lack of activity led to obesity and anaemia cannot be determined from the results of the present study. While the present study investigated dieting behaviours, it did not ask for a complete food recall which could have led to different interpretations of what can junk food' mean.

\section{Conclusions}

Overweight, obesity and anaemia are prevalent among female university students in Dubai. The present study found associations between anaemia, lack of physical activity and percentages of total body fat among young female adults. This may be related to unbalanced diets and preferences for junk food as reported in the present study. Health promotion and nutritional education programmes are needed to reduce the prevalence of anaemia, overweight and obesity among female university students.

Further studies are required to investigate the detailed dietary habits of overweight and obese young adult females with anaemia.

\section{Acknowledgements}

The author would like to acknowledge Zayed University for providing the funding to conduct the present study. Gratitude also goes to all students who participated in the present study.

The present study was supported by Zayed University Start-Up Project (grant no. R14074: 2014-2015).

The author declares that she has no competing interests.

\section{References}

1. Flegal KM, Carroll MD, Kit BK, et al. (2012) Prevalence of obesity and trends in the distribution of body mass index among US adults, 1999-2010. JAMA 307, 491-497.

2. World Health Organization (2000) Obesity: Preventing and Managing the Global Epidemic. Report of a WHO Consultation. WHO Technical Report Series 894. Geneva: WHO.

3. Kassebaum NJ, Jasrasaria R, Naghavi M, et al. (2014) Plenary paper. Red cells, iron, and erythropoiesis: a systematic analysis of global anemia burden from 1990 to 2010. Blood J 123, 615-625.

4. De Andrade Cairo RC, Rodrigues Silva L, Carneiro Bustani N, et al. (2014) Iron deficiency anemia in adolescents; a literature review. Nutr Hosp 29, 1240-1249.

5. Sachdev HP \& Gera T (2013) Preventing childhood anemia in India: iron supplementation and beyond. Eur J Clin Nutr 67, 475-480.

6. Urbano MR, Vitalle MS, Juliano Y, et al. (2002) Iron, copper and zinc in adolescents during pubertal growth spurt. J Pediatr 78, 327-334.

7. Vaskonen T (2003) Dietary minerals and modification of cardiovascular risk factors. J Nutr Biochem 14, 492-506.

8. Zimmermann MB, Zeder C, Muthayya S, et al. (2008) Adiposity in women and children from transition countries predicts decreased iron absorption, iron deficiency and a reduced response to iron fortification. Int J Obes 32, 1098-1104.

9. Menzie CM, Yanoff LB, Denkinger BI, et al. (2008) Obesity-related hypoferremia is not explained by differences in reported intake of heme and nonheme iron or intake of dietary factors that can affect iron absorption. J Am Diet Assoc 108, 145-148.

10. Lecube A, Carrera A, Losada E, et al. (2006) Iron deficiency in obese postmenopausal women. Obesity 14, 1724-1730.

11. Prochnik Estima CC, da Costa RS, Sichieri R, et al. (2009) Meal consumption patterns and anthropometric measurements in adolescents from a low socioeconomic neighborhood in the metropolitan area of Rio de Janeiro, Brazil. Appetite 52, 735-739.

12. Levy RB, Castro IR, Cardoso LO, et al. (2010) Food consumption and eating behavior among Brazilian adolescents: National Adolescent School-Based Health Survey (PeNSE), 2009. Cien Saude Colet 15, 3085-3097.

13. Yanoff LB, Menzie CM, Denkinger B, et al. (2007) Inflammation and iron deficiency in the hypoferremia of obesity. Int J Obes 31, 1412-1419.

14. Pinhas-Hamiel O, Newfield RS, Koren I, et al. (2003) Greater prevalence of iron deficiency in overweight and obese children and adolescents. Int J Obes 27, 416-418.

15. Moayeri H, Bidad K, Zadhoush S, et al. (2006) Increasing prevalence of iron deficiency in overweight and obese children and adolescents (Tehran Adolescent Obesity Study). Eur J Pediatr 165, 813-814.

16. Nead KG, Halterman JS, Kaczorowski JM, et al. (2004) Overweight children and adolescents: a risk group for iron deficiency. Pediatrics 114, 104-108.

17. Al-Sayes F, Gari M, Qusti S, et al. (2011) Prevalence of iron deficiency and iron deficiency anemia among females at university stage. J Med Lab Diagnosis 2, 5-11. 
18. World Health Organization (2007) Assessing the Iron Status of Populations: Annex 1: Indicators of the Iron Status of Populations: Red Blood Cell Parameters. Geneva: WHO.

19. Low S, Chin MC \& Deurenberg-Yap M (2009) Review on epidemic of obesity. Ann Acad Med Singapore 38, 57-65.

20. Paley CA \& Johnson MI (2018) Abdominal obesity and metabolic syndrome. BMC Sports Sci Med Rehabil 10, 881-887.

21. Micozzi MS, Albanes D \& Stevens RG (1989) Relation of body size and composition to clinical biochemical and hematologic indices in US men and women. Am J Clin Nutr 50, 1276-1281.
22. De Benoist B, McLean E, Egli I, et al. (2008) Worldwide Prevalence of Anemia 1993-2005: WHO Global Database on Anemia. Geneva: WHO.

23. Aigner E, Feldman A \& Datz C (2014) Obesity as an emerging risk factor for iron deficiency. Nutrients 6, 3587-3600.

24. Massawe SN, Urassa EN, Nyström L, et al. (2002) Anaemia in women of reproductive age in Dar-es-Salaam, Tanzania. East Afr Med J 79, 461-466.

25. Bentley ME \& Griffiths PL (2003) The burden of anemia among women in India. Eur J Clin Nutr 57, 52-60. 